Ricardo Donoso

\title{
Una figura singular: don Simón Rodríguez
}

34: fines de 1924 fueron solemnemente sepultados, en el Panteón de los Próceres de la capilal del Rimac, los restos mortales de don Simón Rodriguez, que por un feliz acaso fueron hallados en Paita, Se han salvado asi del olvido las cenizas del singular americano que holló con su planta inquieta dos continentes, y sus pobres huesos disfrutan ahora del reposo que no encontraron en su trajinante y peregrina existencia.

Ningún americano actuó tal vez en la pasada centuria en un escenario más vasto que don Simón Rodríguez, dejando por doquier la huella de su genio excéntrico y original. Excepción hecha de Irisarri, ni Bello, ni Garcia del Rio, ni Mitre, ni Sarmiento, ni Vicuña Mackenna, todos hombres de pluma y de pensamiento, tuvieron una tan movediza existencia como la suya. -No quiero parecerme a los árboles, decia. que echan raíces en un lugar y no se mueven sino al viento, al agua, al sol, a todo lo que marcha sin cesars. Desde Francia hasta la lejana Rusia, desde las islas británicas hasta la peninsula italiana, en Europa, y todos los paises que bañan las aguas del Pacifico. en América, recorrió con afán de peregrino y curiosidad insaciable.

SU VIDA

La decisiva influencia que tuvo en la formación intelectual de Bolivar, que justifica el titulo de Maestro del Libertador que se 
le ha dado, su apóstolica consagración a la enseñanza, y la originalidad de sus ideas, que hacen de èl el primer sostenedor y propagandista de las doctrinas socialistas en América, bastan para dar a don Simón Rodriguez un señalado lugar en la historia americana, y para recordar su personalidad como una de las más acentuadas y originales que aparecen en nuestro escenario durante la última centuria.

La vida misma de Rodriguez-desorientada, trajinante, activa, llena de puntos obscuros-es un aspecto más que aguza la curiosidad para ocuparse de ella. Lo poco que se sabe de sus primeros años apenas si es el eco, recogido con acucioso alecto. de una vaga e incierta fradición. De sus relaciones e influencia con Bolivar habló éste extensamente en su famosa carta de 1804 a Fanny du Villars, en la que lo caracteriza comn el compañero de su infancia, el confidente de su adolescencia, el mentor cuyos consejos han tenido siempre en él tanta influencia. Juntos recorrieron. Bolivar y Rodriguez. parte de Francia y la mayor parte de la peninsula italiana, para separarse a fines de 1805 . Ocurre aqui una de las más largas lagunas en la vida del inquieto caraqueño, que se prolonga por cerca de cuatro lustros. De lo que fué su existencia en esos años. lo más importante tal vez en la formación de su cultura y en su orientación ideológica, escribió él, años después. lo siguiente: -Permaneci en Europa por más de veinte años: Irabajé en un laboratorio de química industrial, en donde aprendi algunas cosas: concurri a juntas secrelas de carácler socialista: oi de cerca al padre Enfantin, a Olindo Rodriguez, a Pedro Leroux y a otros muchos que funcionaban como apóstoles de la secta: estudié un poco de literatura: aprendi lenguas, y regenté una escuela de primeras letras en un pueblecito de Rusia.

A fines de 1823 arriba don Simón Rodriguez a Colombia y el Libertador se apresura a escribirle aquella su famosa carta de Pativilca, en la que le dice: ‘Ud. formó mi corazón para la libertad. para la justicia, para lo grande, para lo hermoso. Los días trascurren rápidos y el inquieto caraqueño no puede ir a echarse en los brazos de su glorioso discipulo. Yo no he 
venido a América, le escribia desde Guayaquil en Enero de 1825. porque naci en ella, sino porque tratan sus habitantes ahora de una cosa que me agrada. y me agrada porque es buena, porque el lugar es propio para la conferencia y para los ensayos, y porque es usted quien ha suscitado y sostenido la idea., Por fin ese mismo año maestro $y$ discípulo logran reunirse en Lima, y poco después enderezar juntos rumbo al altiplano.

En el Allo Perú iba don Simón Rodriguez a pretender realizar el sueño de su vida: el establecimiento de casas de educación, que se ajustarian a su plan personalisimo y original, el fruto de las cuales le permitiria echar las bases de una república ideal, formada por ciudadanos laboriosos, y destruir de raiz la religión de Jesucristo. A pesar de toda la benevolencia con que lo trató el general Sucre, pronlo el sueño del incorregible ideólogo se derrumbó estrepitosamente. Bolivar es un paño de lágrimas, y el Libertador lo socorre generosamente. Se queja don Simón de la incomprensión de las gentes, de la hostilidad a sus propósilos, del abandono en que lo deja el gobierno. -Dos ensayos llevo hechos en América y nadie ha traslucido el espíritu de mi plan,. decía. En Chuquisaca compuso su defensa de Bolivar y de sus compañeros de armas, que circuló manuscrita, y sólo fué dada a la estampa dos años después en Arequipa.

\section{EN CHILE}

En los años siguientes anduvo el trajinante venezolano de un lado para otro en el Perú, hasla que vino a dar con su humanidad en Chile. Es dificil determinar con exactitud la lecha del arribo de don Simón Rodriguez a las tierras de Arauco, pero ya en 1834 se hallaba en Concepción entregado de lleno a sus labores educativas. Parece que no lueron vientos de prosperidad los que por estos dias soplaron al animoso preceptor, pues no hay ningún rastro de sus actividades en los años siguientes. En los últimos años de la administración del general Prielo lo 
encontramos en Santiago. frecuentando el trato del venerable Bello y de otras personalidades chilenas. Fué tal vez entonces cuando lo conoció don Viclorino Lastarria, quien en sus .Recuerdos literarios: lo pinta como sun viejo enjulo, trasparente, cara angulosa y venerable, mirada osada e inteligente, cabeza calva y de ancha Trentes.

Con ese su amor rabioso a la liberlad - ela libertad me es más querida que el bienestar, decia - don Simón Rodriguez no encuentra arraigo en ninguna parle. Sueña con un viaje a Europa, todo le fastidia y no ve las horas de poder abandonar el suelo americano. Estoy con un amigo, escribía por estos dias, y... Itan bienl que sólo el deseo de volverme a Europa me hace emprender viaje. Este deseo me atormenta: en América no sirvo para nada: volviéndome a paises donde he pasado una gran parte de mi vida, espero pasar la que me queda, tan felizmente como antes... esto es, sin enemigos. Dero de alli a poco lo hallamos en Valparaiso, regentando una pobre escuela de primeras letras y... fabricando velas. Sobre su puerta habia escrito esta leyenda:- Luces y virtudes americanas, esto es, velas de sebo, paciencia, jabón, resignación, cola fuerte, amor al trabajo.

Hombre sin prejuicios, con una carencia total de preocupaciones secundarias. Rodriguę sienta a su sirviente a su mesa. y no tiene escrúpulos en vivir públicamente con una india, en quien habia tenido dos hijos, que amaba tiernamente y regocijaban sus viejos dias. Cuando a principios de $1840 \mathrm{el}$ eminente don Luis Antonio Vendel Heyl vió a Rodriguez en Valparaiso tuvo ocasión de constatar que ese su desprecio por las preocupaciones sociales era una de las causas que lo mantenian en un amargo aislamiento.

Pero en Chile iba a realizar don Simón Rodriguez - no en Lima como apunta Lozano y Lozano $\left({ }^{*}\right)$-la máxim aaspiración de su vida: la publicación de sus escritos: ese año 40 la imprenta de El Mercurio da a la estampa, en un folleto de 80

(*) .El maestro del Liberfador,. pág. 190. 
páginas. Sociedades americanas en 1828. Como serán y como podrían ser en los siglos venideros. Primera parle. Luces y virtudes sociales».

Ya a principios de ese mismo año don Simón Rodriguez habia publicado en El Mercurio, que por esos dias era de propiedad del sanjuanino José Luis Calle, una serie de arliculos que eran la mejor anticipación de su escrito. Difícil sería dar una idea, por somera que fuera, de la indole de los articulos del trajinante caraqueño en El Mercurio: hay en ellos una originalidad tan personalisima, domina una carencia tal de propósilos determinados, que casi podrian juzgarse como una colección de aforismos, de tendencia filosófica y moral. La manera de composiciōn es también tan personal y suya, sin sujetarse a ninguna de las normas corrientemente acepladas, que ostenta un sello caracteristico inconfundible. Borda don Simón Rodriguez algunas glosas a su tratado sobre las luces y las virtudes sociales. ¿Cuáles son para él las virtudes sociales? El orden, la unión. la paz y la amistad. Ya en su décimo articulo, de los quince que publicara, y que el diario porteño inserta en su columna editorial, como todos los anteriores, se ocupa de su tema favorito. la educación de los niños. Los hombres no esludian bien la infancia, dice. Es menester preocuparse de los niños para enseñarles a reflexionar. Hay que formar la opinión pública mediante la difusión de la enseñanza y en este sentido no se ha hecho nada en América.

publicó lambién don Simón Rodríguez en El Mercurio algunos fragmentos de su defensa de Bolivar, en la que hay páginas admirables que revelan la agudeza de su espiritu y la sangrienta mordacidad de su pluma.

\section{SUS IDEAS SOBRE INSTRUCCIÓN PÚBLICA}

Ya en su defensa de Bolivar había esbozado el excéntrico caraqueño cierlos aspectos de su plan de instrucción pública. y los propósilos que habian guiado su acción docente en Chuquisaca. El plan de educación popular, escribió alli, de des- 
tinación a ejercicios útiles y de aspiración fundada a la propiedad. lo mandó ejecutar Bolivar en Chuquisaca. Expidió un decreto para que se recogiesen los niños pobres de ambos sexos, no en casas de misericordia, a hilar por cuenta del Estado; no en conventos a rogar a Dios por sus bienhechores; no en cárceles a purgar la miseria o los vicios de sus padres; no en hospicios, a pasar sus primeros años aprendiendo a servir para merecer la preferencia de ser vendidos, a los que buscan criados fieles o esposas inocentes.

-Los niños se habian de recoger en casas cómodas y aseadas, agregaba, con piezas destinadas a talleres, y estos surtidos de instrumentos, y dirigidos por buenos maestros. Los varones debían aprender los tres oficios principales, albañileria, carpinteria y herreria, porque con tierra, maderas y metales se hacen las cosas más necesarias, y porque las operaciones de las arles mecánicas secundarias dependen del conocimiento de las primeras. Las hembras aprendian los servicios propios de su sexo. considerando sus luerzas, se quitaban, por consiguiente, a los hombres, muchos ejercicios que usurpan a las mujeres.

-Todos debian estar decentemente alojados, vestidos, alimenlados, curados y recibir instrucción moral. social y religiosa. Tenian, fuera de los maestros de cada oficio, agentes que cuidaban de sus personas y velaban sobre su conducta, y un direclor que trazaba el plan de operaciones y lo hacia ejecutar.

-La intención no era, como se pensó, apunlaba más adelante. llenar el pais de artesanos rivales o miserables, sino instruir y acostumbrar al trabajo para hacer hombres útiles. asignarles tierras y auxiliarlos en su establecimiento... era colonizar el pais con sus propios habitantes. Se daba instrucción y oficio a las mujeres para que no se prostituyesen por necesidad, ni hiciesen del matrimonio una especulación para asegurar su subsistencia..

Una innovación tan atrevida no pudo menos de causar, sorpresa primero, e indignación después, en el pacato y religioso ambiente colonial de la docla Chuquisaca. No era. además, don Simón Rodriguez hombre de espírilu ponderado y prudente: en todas partes se jactaba de su amistad con Bolivar, en Cocha- 
bamba peleó con medio mundo calificándolos de ignorantes y brutos, vivia amancebado, y en cierta ocasión dijo, ioh imperdonable herejial. que antes de seis años él destruiria en Bolivia la religiōn de Jesucristo. No es de extrañar, pues, que Rodriguez. por su genio altivo y extravagante, se concilara la animosidad chuquisaqueña. Hasta el mismo benemérito y ecuánime Sucre llevó sus quejas hasla el conocimiento del Liberlador. - Considero a don Samuel (por el nombre de Samuel Róbinson que también se le daba). le escribia, un hombre muy instruido. benéfico cual nadie, desinteresado hasta lo sumo, y bueno por carácter y por sistema: pero lo considero también con una cabeza alborotada con ideas extravagantes, y con incapacidad para desempeñar el puesto que tiene bajo el plan que él dice y que yo no sé cual es; porque diferentes veces le he pedido que me traiga por escrito el sistema que él quiere adoptar. para que me sirva de regla, y en ocho meses no me lo ha podido presentar. Sólo en sus conversaciones dice hoy una cosa y mañana olra.s

El ruidoso fracaso de su ensayo de Chuquisaca no modificó en nada las ideas de don Simón Rodriguez sobre educación. alribuyendo aquel a la incomprensión de las gentes y a los cortos medios que se facilitaron para ponerlo en práctica. Por eso en su defensa de Bolivar se quejaba amargamente de los tropieżos que se le pusieron para la realización de su magno proyecto, y de la ceguera de las autoridades. Apuntan en ese su proyecto conceptos fundamentales de lo que debia ser un verdadero plan de educación popular, que colocan a don Simón Rodriguez entre uno de los precursores de la difusión de la primera enseñanza en Hispano América. El establecimiento destinado a la educación, deciá, es social: su plan es nuevo: sus propósitos, formar ciudadanos para la república. La enseñanza no debe responder a fines piadosos, ni ser el objeto de la vanidad de los poderosos. Señalaba don Simón las condiciones que debia reunir el maestro con un acierto y una clarovidencia que no repudiarian hoy el más exigente de los pedagogos.

Con la realización de su plan pretendia don Simón Rodri- 
gucz transformar a Bolivia en una república democrática, a sus habitantes en verdaderos ciudadanos y a una considerable porción de la América en un pais culto regido por instituciones republicanas.

Pero fué en Chile donde Rodriguez iba a tener lá satisfacción de publicar los que él llamaba sus borradores sobre instrucción pública, qque luvieron principios a fines del siglo pasado, en Europa, donde vivi enseñando por espacio de muchos años, o sea su folleto. Sociedades americanas en 1828. Luces y virtudes sociales». Consagra en él el maestro caraqueño la introducción a esbozar su plan de educación popular, a criticar el sistema educativo existente, y a formular sus ideas politicas y sociales. La instrucción pública en el siglo XIX clama por una reforma, decía, y es la América la única llamada a cmprenderla en las actuales circunstancias. En esta reforma. América no debe imitar servilmente, sino que debe ser original; las reformas deben ser graduales para que sus efectos sean durables y hay que seguir las enseñanzas de la experiencia. Es un deber de los gobiernos republicanos difundir la enseñanza: -Asuma el gobierno las funciones de padre común, escribia: generalice la instrucción y el arte social progresará, como progresan todas las artes que se cultivan con esmero., Para disfrular del goce de la ciudadania los hombres deben prepararse mediante la adquisición de cuatro especies de conocimienios: instrucción social, corporal, técnica y cientifica. La instrucción que necesita el hombre es la que le debe dar el conocimiento de las obligaciones que debe llenar para con la sociedad en que vive. Concebía don Simón Rodriguez las labores educativas como una misión desinteresada y altisima, como un apostolado laico, y que él realizó instruyendo el más puro y noble paradigma. Hacer negocio con la educación es.... escribia, diga cada lector todo lo malo que pueda, todavia le quedará mucho que decirs. Las funciones de un maestro y de un charlatán. apuntaba en otra parle, son tan opuestas, que no pueden compararse sin repugnancias.

Don Miguel Luis Amunátegui resume en tres punlos funda- 
mentales el sistema educacional de don Simón Rodriguez: dirección exclusiva de la educación por el gobierno; educación general, uniforme y forzosa para todos: educación simultáneamente moral y fisica. que llene las necesidades espirituales y corporales del individuo. Con justificado orgullo apuntaba el eminente historiador chileno que Chile, la más oscura y pobre de las colonias hispano-americanas. Tué una de las primeras en seguir, en su orientación cardinal, el programa educativo trazado por el altivo caraqueño. Pero. sin pretender plantear comparaciones enojosas, bien puede afirmarse que las lineas básicas del sistema formulado por don Simón Rodriguez podria servir, a más de una república indo-latina, para orientar la organización de su servicio de instrucción pública.

\section{SUS IDEAS POLITICAS Y SOCIALES}

Pero el propósilo que guió a don Simón Rodriguez al dar a la estampa su folleto citado no fué sólo el de formular un plan de educación pública, sino el de echar las bases de todo un vasto sistema de organización social. En este sistema el autor venezolano asigna a la educación el primer rango, una imporlancia fundamental y decisiva. Anle todo es el de Rodriguez un credo republicano, del más rabioso y exaltado republicanismo. La instrucción general es el único medio de dar eslabilidad a las instituciones liberales, escribía, Una vez oblenida la educación de los ciudadanos sería llegado el momento de proceder a la colonización del pais por sus propios habilantes. En las repúblicas no debe haber populacho, agregaba, y los pueblos pueden vivir sin reyes y sin congresos. Pensemos en la suerle social de nuestros hijos, más bien que en sus comodidades, dejémosles luces en lugar de caudales, pues la ignorancia es más de temer que la pobreza. Juzgaba don Simón Rodriguez del progreso de las naciones por su organización politica: donde hay un monarca absoluto el pueblo es nulo, consignaba. No es próspero ni libre el pais, agregaba, en el que disfrutan de comodidades sólo ciertas clases sociales; no es próspero el que cuenta millo- 
nes de miserables. No hay libertad donde hay amos, ni prosperidad donde la casualidad dispone de la suerte social.. Para clasificar los gobiernos en monárquicos o republicanos no atendia don Simón a las caracteristicas de la organización de la administración, sino a la circunstancia de que identificaran o no sus intereses con los del pueblo. Es monárquico. argüia. el gobierno que procura el bienestar de las clases privilegiadas, y republicano el que se ocupa del mejoramiento de todos en general.

¿Cuál era el ideal de don Simón Rodriguez? Soñaba el singular venezolano con la creación de una república igualitaria. sin castas privilegiadas, ni clases dominantes, en que todos los habitantes disfrutaran por igual de las comodidades y placeres de la vida. a lo que se debia llegar mediante la difusión de la educación general. Aspiración generosa y seductora, sueño inalcanzable y lejano. frágil quimera de un espiritu soñador.

\section{LA INFLUENCIA DE SAINT SIMON Y DE FOURIER}

El eminente profesor Vendel Heyl, que era un sansimoniano ardiente, y conoció a Rodríguez en edad piovecta-tenia 74 años.-nos ha dejado una curiosa página sobre sus conversaciones con el andariego caraqueño. Aun cuando el maestro del Libertador reconocia que había escuchado la palabra ardorosa de Enfantin y Olindo Rodriguez, los más fieles discipulos del autor del Nuevo cristianismo. no comulgaba del todo con los nuevos postulados del sansimonismo. Aceptaba, si, la comunidad de sus ideas con esa su orientación generosa en favor de los desheredados y en ese su propósito de hacer la vida lo más feliz posible para todos.

Declaró don Simón a Vendel Heyl que conocia los nombres de Fourier y. Saint Simon, pero que no habia leido sus obras. ¿Pretendía con esto aparecer como un pensador original, como un reformador personalisimo y único? Es evidente la influencia de la escuela socialista en las ideas politicas y sociales del preceptor venezolano. pero es justo tambiên reconocer la origina- 
lidad de su sistema de reforma social por medio de la instrucción pública. Los reformadores de la escuela socialista contrajeron su atención a las actividades de la vida industrial y social, asignando a la misión educativa un papel bien secundario. Don Simón Rodriguez, por el contrario, hace de su plan de instrucción pública el punto inicial de todo su programa reformador, la piedra fundamental de su edificin social. Ahi estriba la originalidad toda de su sistema. el admirable acierto de sus generosos proyectos, que el correr de los años y el pasar de las generaciones no hacen más que justificar con proyecciones definitivas.

\section{EL OCASO}

Es punto menos que imposible fijar con certeza la fecha de la partida de don Siınón Rodriguez de Chile. Ni el peso de los años, ni los sinsabores de su aporreada existencia, le restaron vehemencia a su pasión trashumante, En 1843 lo hallamos en Ecuador, tres años después en la Nueva Granada, en 1850 está en Quito y poco después en un 'pueblecito a orillas del Titicaca, hasta que cuatro años después lo sorprendió la muerte en un puerto del Perú, arrullado por las aguas de

Pacifico. Ahora reposan sus cenizas, recogidas por piadosas manos, en el Panteón de los Próceres de la vetusta y docta Lima. ITardio homenaje de la posteridad a su noble, soñadora y singular existencia! 